\title{
A ORDEM DO DISCURSO JORNALÍSTICO SOBRE EDUCAÇÃO: UMA ANÁLISE DAS MATÉRIAS DA FOLHA DE S. PAULO DE 1996 A 2006
}

Gisela Maria do Val ${ }^{*}$ Julio Groppa Aquino**

RESUMO: O presente artigo dá a conhecer os resultados de uma investigação das racionalidades e das tensões ético-políticas expressas nas matérias sobre educação escolar veiculadas pelo jornal Folha de S. Paulo, no período de dezembro de 1996 - a partir da promulgação da LDB em vigor - a novembro de 2006. Por meio de uma análise do material empírico orientada por alguns operadores teórico-metodológicos oferecidos por Michel Foucault foi possível atestar, além da proliferação de matérias sobre a temática educacional, que a imprensa escrita arregimenta, de modo reiterativo e circular, concepções reparatórias ou reformistas das práticas escolares contemporâneas, em consonância com as produções acadêmicas, os saberes dos especialistas e as injunções econômicas e políticas. Ao fazê-lo, o discurso jornalístico consagra-se como um potente recurso de governamentalização das atitudes e dos valores partilhados pela população no tocante à natureza e ao raio de ação do trabalho educativo na atualidade.

Palavras-chave: Discurso Jornalístico sobre Educação; Governamentalização; Michel Foucault.

THE ORDER OF JOURNALISTIC DISCOURSE ON EDUCATION: AN ANALYSIS OF FOLHA DE S. PAULO ARTICLES FROM 1996 TO 2006

ABSTRACT: This paper provides the outcome of an investigation of the rationalities and ethical-political tensions expressed in the articles on school education conveyed by the newspaper Folh a de São Paulo, from December 1996 - from the enactment of the Brazilian Law of Guidelines and Bases of National Education in force - to November 2006. Through an analysis of the empirical data headed by some of Michel Foucault's theoretical and methodological operators, it was possible to verify that, besides the proliferation of educational reports on the newspaper, the printed press aggregates, in a repetitive and circular way, reparative or reformist conceptions of contemporary school practices, in line with the academic production, the experts' knowledge, and the economic and political

\footnotetext{
*Licenciada em pedagogia, mestre e doutoranda em educação pela Faculdade de Educação da Universidade de São Paulo (FEUSP); É também professora do Ensino Fundamental. E-mail: giselaval@usp.br

* *Livre-docente da Faculdade de Educação da Universidade de São Paulo (FEUSP); Mestre e doutor pelo Instituto de Psicologia da mesma universidade, com pos-doutorado pela Universidade de Barcelona; Pesquisador do CNPq. E-mail: groppaq@usp.br
} 
injunctions. In doing so, the journalistic discourse establishes itself as a powerful resource for the governmentalization of the attitudes and values shared by the population concerning the nature and range of the educational work nowadays.

Keywords: Journalistic Discourse on Education; Governmentalization; Michel Foucault.

[...] o que se esconde sob essa palavra precisa, flutuante, misteriosa, absolutamente simples:

"Hoje".

Michel Foucault (2010)

O jornalismo é um campo de produção de discursos que opera com vistas à apropriação e à difusão de ideias tidas como verdadeiras, o que, a nosso ver, garante-lhe a posição de lócus privilegiado para a problematização das formas de governo dos homens na atualidade. A imprensa escrita observa e difunde acontecimentos, produzindo narrativas que, em vez de descrevê-los, forjam o que ali é apresentado, por meio de um deslocamento do imaterial do acontecimento para uma identidade fixada no interior de um discurso que delimita tanto o dizível quanto o que não é permitido dizer (FOUCAULT, 2004).

Se, conforme assevera Michel Foucault (2007), o discurso é sempre dispersão, constituído que é por elementos que não estão ligados por nenhum princípio incondicionado, o que fornecerá a uniformidade do discurso jornalístico será o entrelaçamento por ele operado entre "os objetos, os tipos de enunciação, os conceitos, as escolhas temáticas”, todos englobados em uma "regularidade (uma ordem, correlações, posições e funcionamentos, transformações)" (p. 43).

Partindo da evidência de que a educação escolar tem-se apresentado como um tema recorrente nas matérias jornalísticas, o trabalho de investigação por nós levado a cabo objetivou traçar um mapeamento crítico das racionalidades e das tensões ético-políticas materializadas nos textos sobre educação veiculados pelo jornal Folha de S. Paulo no período de dezembro de 1996 (data da promulgação da Lei de Diretrizes e Bases da Educação Nacional vigente) a novembro de 2006 - uma década crucial para a história da educação brasileira, tendo em vista a consolidação de uma educação alardeada como democrática, plural e redentora, segundo quaisquer dos setores nela envolvidos. 
A análise do corpus objetivou, igualmente, evidenciar uma espécie de disputa acirrada entre a autorização discursiva autoconferida pelo jornalismo e aquela dos protagonistas escolares ali aludidos (desde alunos e professores até gestores e políticos) por intermédio da formulação, pelo jornal, tanto de ações específicas quanto de modelos gerais supostamente mais eficientes e produtivos para o enfrentamento dos problemas da educação nacional. Mais especificamente, as matérias analisadas parecem portar a aspiração inconteste de instruir o público leitor acerca dos requisitos necessários para atingir uma dita educação de qualidade, conforme, claro está, os parâmetros eleitos pela linha editorial do jornal em questão.

Não obstante suas peculiaridades empíricas, jornalismo e educação encontram, aqui, um ponto de confluência, como práticas sociais de vocação expressamente pedagogizante, tendo, no caso do primeiro, a própria opinião pública como alvo - incluídos aí os próprios protagonistas escolares. Disso decorre que a mídia impressa, no quadrante aqui eleito, projeta-se como um lócus discursivo no interior do qual a questão educacional ultrapassa o status de temática de destaque, convertendo-se propriamente num solo empírico para a jurisdição e, no limite, a ingerência jornalística.

Com efeito, são notórias as prescrições disciplinares e reguladoras presentes nas matérias sobre educação na Folha de S. Paulo ao espargirem determinados conhecimentos e maneiras de produzir ações. A maioria dos textos por nós analisados parece pretender ensinar à escola como ela deveria operar, ofertando a seus protagonistas modos mais adequados ou atualizados de educar e, com isso, professando um ideal de sujeito a ser formado, bem como um modelo de sociedade a ser concretizado. A eficácia argumentativa do discurso jornalístico sobre educação, no caso aqui em tela, parece residir na disseminação de uma responsabilização que traz em seu bojo a promessa de desenvolvimento individual e coletivo, resultando numa participação ativa na redenção e no aperfeiçoamento da escola e, por extensão, da sociedade.

Tal quadro ético-político demonstra o papel ativo do jornalismo no domínio público, o qual se desenrola por meio da imposição de um horizonte social pedagogizado: a apresentação do mundo baseada nos modos pelos quais ele deveria obrigatoriamente ser vivido. Trata-se de um modus operandi que finda por lhe chancelar uma posição estratégica na 
produção e difusão de certos discursos, bem como no arrefecimento ou, no limite, rarefação de outros discursos possíveis.

A partir de certo estranhamento em relação à discursividade sobre a educação formal em um jornal de ampla circulação como a Folha de $S$. Paulo, mas admitindo tal discursividade como uma vigorosa estratégia de educação não formal e permanente dos próprios cidadãos, propusemo-nos a problematizar as narrativas prevalentes nesse âmbito, tomando-as como vetores discursivos que interagem decisivamente com a produção de determinadas imagens sociais acerca da boa escola. Destarte, a hipótese central de nossa investigação é a de que o discurso jornalístico, ao escrutinar, ajuizar e prescrever determinados acontecimentos da seara educativa, incita práticas que engendram relações de poder/saber não apenas com e pelos leitores, mas entre os cidadãos como um todo, consistindo num potente recurso de governamentalização, segundo a acepção foucaultiana, das atitudes e dos valores partilhados pela população no tocante à natureza e ao raio de ação do trabalho educativo.

\section{DO FATO À VERDADE: TRANSPOSIC̣ÕES}

Michel Foucault - referência teórico-metodológica capital de nossa investigação - aceitou, em 1978, o convite do diário italiano Corriere della Sera para que fosse ao Irã e redigisse uma série de artigos sobre o que então se passava naquele país. Para o pensador, a exploração de um acontecimento fulgurante como a Revolução Islâmica poderia pôr em questão, além do próprio jornalismo, certos processos de subjetivação e o modo como eles eram atravessados por relações de poder. Seu interesse residia não apenas no jogo que barra, interdita e invalida o discurso das massas, mas também no papel da mídia na profusão de determinadas ideias partilhadas coletivamente. Didier Eribon (1990) lembra que "[...] ele [Foucault] se questionava muito sobre o papel dos jornais na circulação das ideias e principalmente sobre a confusão generalizada dos valores [...]” (p. 273).

O que inquietava o intelectual francês a esse respeito era o papel da mídia impressa na edificação, na validação e na circulação de determinadas verdades sobre o mundo presente, sendo tais processos entendidos por ele como "[...] um conjunto de regras segundo as quais se distingue o 
verdadeiro do falso e se atribui ao verdadeiro efeitos específicos de poder [...]” (DELEUZE, 2006, p. 13).

Assim, os jogos de veridicção do real dependeriam, segundo Foucault, de três elementos: os regimes de verdade e suas relações intrínsecas com os campos de saber (FOUCAULT, 2006a); as relações de poder que determinam, junto com os saberes, os tipos de normatividade dominantes (FOUCAULT, 2004); bem como os modos de relação consigo mesmo e com o outro, via determinadas formas de subjetivação (FOUCAULT, 2006b). Os dispositivos de produção da verdade instituem o indivíduo como protagonista de tal produção, o que se desdobra em diferentes níveis: no da linguagem, configura-se o sujeito falante; no do pensamento, o sujeito racional; no do cuidado de si e do outro, o sujeito moral.

Múltiplos são os espaços para o fluxo contínuo de dizeres verdadeiros; sem dúvida, a imprensa escrita é um deles. Os textos jornalísticos e seus temas diversificados compõem narrativas que enunciam acontecimentos, legando ao leitor uma abundante massa de informações. Na mídia impressa, a oferta de notícias orienta-se, sobretudo, pela lógica da visibilidade: quanto mais informação, mais fácil seria desvendar a suposta integralidade da verdade, em suas diferentes facetas.

Desse modo, dois fenômenos são fundamentais na estratégia jornalística da disseminação de informação: a observação e a incitação. Podemos definir a primeira como sendo algo da ordem de um olhar diligente. As matérias veiculadas levam a crer que a mirada jornalística compareceria em todos os lugares: relatam-se ações específicas, inferindo suas intenções; expõem-se os acontecimentos em quaisquer contextos - dos gabinetes legislativos aos consultórios médicos, passando pelas salas de aula etc. Trata-se, assim, de um olhar seletivo, classificatório e produtivo, responsável por subsidiar opiniões que, por sua vez, ajuízam ações e práticas ora como nocivas, ora como proveitosas.

A incitação levada a cabo pelas matérias opera num timbre semelhante. Relata-se muito; investiga-se em grandes proporções. Assim, uma narrativa que pretendesse ser verdadeira basear-se-ia necessariamente na averiguação minuciosa dos fatos: quanto maior a quantidade de fatos relatados, mais abrangente seria sua apuração. Em outros termos, pressupõe-se que quanto mais abrangente for o número de informações, mais fidedigna será a narração do acontecimento em pauta. Tal ideia, propagada e autenticada 
pelos meios de comunicação, autoriza a profusão de informações tidas como confiáveis, porque alegadamente ancoradas no real.

Entretanto, a nosso ver, ao se problematizar a concepção de realidade ali disposta, questionando sua unicidade, compreende-se a disseminação de informações como uma estratégia do dispositivo comunicacional, voltado à produção de regimes de veridicção do real, e não à revelação deste. Pode-se, assim, entender a verdade ali pleiteada não como correspondência dos fatos, mas como efeito de enunciados que têm sentido tão somente no horizonte de seu uso. Nessa perspectiva, a repetição afigura-se como estratégia prevalente de fixação, de persuasão, isto é, uma tentativa de naturalização de sentidos considerados inequívocos, bem como de estabelecimento dos parâmetros de inteligibilidade pelos quais julgamos os fatos apresentados.

Se compreendermos que os sentidos de determinado acontecimento podem ser múltiplos e que, portanto, não existe uma essência primeira sua a ser revelada, poderemos deduzir que as narrativas jornalísticas criam realidades lastreadas em bases alegadamente empíricas, mas que, a rigor, estão subsumidas a regimes de saber/veridicção já instituídos. Isso significa que a imprensa é um sistema de informação que opera por meio de palavras de ordem. Como argumenta Gilles Deleuze (1999), essas

[...] nos comunicam informações, nos dizem aquilo que julgam que somos capazes ou devemos ou temos a obrigação de crer. Ou nem mesmo crer, mas fazer como se acreditássemos. Não nos pedem para crer, mas para nos comportar como se crêssemos. Isso é informação, isso é comunicação; à parte essas palavras de ordem e sua transmissão, não existe comunicação. O que equivale a dizer que a informação é exatamente o sistema do controle [...] (p. 5).

Palavras de ordem, no contexto do pensamento deleuziano, não remetem a um comando imperativo, mas ao vínculo dos enunciados com pressupostos subentendidos. Trata-se de pontos de vista implícitos que transpassam os assuntos abordados, sendo englobados por um solo comum de significações de véspera.

Os jornais dizem-nos, portanto, o que é essencial "pensar, reter, esperar... uma vez que o enunciado realiza um ato e que o ato se realiza no enunciado" (DELEUZE; GUATTARI, 2008, p. 17). Todavia, é preciso não consagrar ao jornalismo, e à mídia em geral, um papel de oráculo, uma vez que ambos se inserem em toda uma rede de relações, discursivas ou não, atadas 
a um mecanismo que opera sempre em conflito entre posições, por meio de embates e consensos, interdições e autorizações, inclusões e exclusões. Trata-se de um jogo de fricções que impele as ações dos sujeitos, respeitando e invadindo fronteiras delineadas conforme demandas, necessidades de administração e gerência de condutas. Tal movimento oscilatório é perpassado por forças que incitam diferentes palavras de ordem, diferentes grades de significação e, portanto, diferentes processos de subjetivação.

O texto jornalístico com pretensão ao estatuto de confiabilidade e veracidade deve estar fundamentado em formas racionais de saber, muitas vezes fortalecidas por testemunhos (FOUCAULT, 2005), prática usual do modus operandi jornalístico. A produção e a fixação da verdade, nesse caso, processam-se, sobretudo, por meio do expediente da confissão dos protagonistas da situação. Se, por um lado, em determinadas situações, os sujeitos identificam sua verdade por meio de outros - por exemplo, pelas sentenças dos especialistas -, por outro, quando o testemunho de professores e alunos é convocado nas matérias, arregimenta-se uma estratégia pela qual o sujeito é chamado a falar de si. Trata-se de uma enunciação do eu (FOUCAULT, 1997) com vistas a um engajamento do sujeito em relação à verdade que ele manifesta. Ao propor a vinculação do sujeito à obrigação de dizer a verdade sobre aquilo que ele próprio anuncia, a enunciação qualifica-o como um professor sofrido, um aluno revoltado etc. e faz com que ele se reconheça intimamente naquilo que desponta diante dele como sendo sua própria história.

A confissão jornalística parece operar, pois, em duas direções: no plano individual, engaja o sujeito à verdade; no plano coletivo, cria algo cuja existência não pode ser contestada, legitimando uma verdade proveniente de seus próprios informantes.

A linguagem da mídia impressa é, assim, ação pura, performatividade inconteste. Na narrativa jornalística há sempre movimento - acusações, insinuações, questionamentos, justificativas - incitando um posicionamento dos interlocutores. Os enunciados jornalísticos apresentam-se, portanto, como elos de uma corrente de enunciação histórica e socialmente organizada, inserida em regimes de verdade preexistentes que renascem no próprio ato daquela enunciação. 


\section{AS PRODUC̣ÕES ACADÊMICAS SOBRE A EDUCAC̣ÃO ESCOLAR NA MÍDIA}

A atuação da mídia é alvo de várias produções acadêmicas. Uma parte significativa da literatura acadêmica a ela dedicada elege-a como aliada instrumental na construção do conhecimento, considerando os aspectos educacionais e informacionais, bem como as possibilidades de transformação das práticas educativas; outra parte focaliza o discurso da mídia e analisa criticamente de que forma os postulados de identidades processam-se no interior dos enunciados, isto é, como eles são transmitidos aos leitores, quais construções de significados e valores são propostas e de que maneira os indivíduos relacionam-se com tais enunciados.

Algumas pesquisas que se dedicaram a investigar o discurso da mídia sobre educação analisaram revistas educacionais específicas. Entre tais estudos, temos as dissertações de mestrado de Edivania Pinheiro Ferreira Cancian (2008), intitulada $O$ discurso de uma revista especializada em educação: um olhar sobre a construção metafórica do professor, e de Fernanda Romanezi da Silveira (2006): Um estudo das capas da Revista Nova Escola: 1986-2004.

As investigações que pretenderam analisar as publicações de grande circulação concentram-se nas revistas semanais. Nesses trabalhos, as análises convergem para as representações que a educação adquire nas narrativas jornalísticas, por intermédio das imagens produzidas e reproduzidas por tais meios de comunicação. Um dos exemplos é a dissertação de Ana Paula Fonseca (2008), A construção da educação na revista Veja, em que a autora leva a cabo uma análise sobre as imagens da educação que figuraram nas capas da revista. Há também a tese de doutorado $A$ escola na mídia: nada fora do controle, de Cristianne Maria Famer Rocha (2005), que analisou as reportagens publicadas nas revistas $V$ eja e IstoÉ sobre violência escolar com o propósito de compreender as condições que permitem que a instituição escolar modernize-se para continuar produzindo corpos e mentes dóceis, disciplinados e controlados; e $A$ mídia como dispositivo da governamentalidade neoliberal: os discursos sobre educação nas revistas Veja, Época e IstoÉ, tese de doutorado de Vera Regina Serezer Gerzson (2007), que empreendeu um estudo sobre como estratégias das relações de poder neoliberais utilizam as práticas incorporadas no discurso das mídias como verdades que circulam nos espaços públicos. Seguindo uma linha de análise semelhante, Geraldo Sabino Ricardo Filho (2003) produziu a dissertação $A$ boa escola do discurso 
da mídia, em que apresenta as considerações sobre educação veiculadas na revista Veja e elabora um importante estudo sobre a representação midiática do conceito de boa escola.

$\mathrm{Na}$ Universidade Federal do Rio Grande do Sul, duas pesquisadoras, em especial, dedicaram-se ao estudo dos meios de comunicação: Marisa Vorraber Costa e Rosa Maria Bueno Fischer. Tendo Michel Foucault como um dos principais referenciais teóricos, suas investigações, em semelhante medida, são voltadas à análise das mídias como produtoras de identidades, com ênfase nas questões de regulação social por meio dos discursos que incitam determinados processos de subjetivação. As pesquisas dessas autoras desdobram-se em torno de um eixo que aponta o discurso midiático como uma das estratégias mais eficazes de subjetivação.

Dentre as produções de Rosa Maria Bueno Fischer podemos destacar sua tese de doutorado Adolescência em discurso: midia e produção de subjetividade, de 1996, que trata dos discursos da mídia sobre a adolescência, partindo da constatação de que meninos e meninas adolescentes adquirem modelos de identidade principalmente nos textos e imagens dos meios de comunicação. Os trabalhos posteriores de Fischer perseveram no tema da moldagem e da fixação das identidades por processos de subjetivação produzidos pela cultura da imagem por meio dos discursos midiáticos, especialmente aqueles transmitidos pela televisão.

Já dentre as produções de Marisa Vorraber Costa (2000, 2002) sobre essa mesma temática, há trabalhos como: Estudos culturais em educação: mídia, arquitetura, brinquedo, biologia, literatura, cinema..., texto publicado em 2000 sobre as relações entre a mídia e a fabricação de identidades sociais, com foco na produção da Revista Nova Escola; além de um artigo veiculado na Revista Brasileira de Educação em 2002, intitulado Ensinando a dividir o mundo: as perversas lições de um programa de televisão, que expõe a mídia, particularmente a televisão, como um dispositivo que integra o aparato pedagógico das sociedades contemporâneas, sendo responsável por disseminar um conjunto de verdades que compõem o currículo cultural.

Tais trabalhos, com abordagem teórica semelhante à nossa, descrevem o jogo acirrado entre mídia e processos de subjetivação. Segundo essa perspectiva, trata-se de percorrer um caminho analítico pavimentado por ideias que diferem daquelas que apontam o discurso midiático como responsável direto pela alienação dos sujeitos. Partimos, assim, da hipótese 
de que a relação dos sujeitos com a mídia dá-se mais na forma de práticas de incitação do que de sujeição; de exercícios orientados por um tipo de liberdade regulada e não por práticas de dominação; de construções menos forjadas em representações e mais em técnicas de si, as quais descrevem, segundo Foucault (1997),

[...] procedimentos que, sem dúvida, existem em toda civilização, pressupostos ou prescritos aos indivíduos para fixar sua identidade, mantê-la ou transformá-la em função de determinados fins, e isso graças a relações de domínio de si sobre si ou de conhecimentos de si por si [...] (p. 109).

Um trabalho, em específico, utiliza o mesmo lócus de pesquisa que o nosso. A dissertação de Marcos Luiz Cripa (2008) apresenta um estudo comparativo sobre a cobertura jornalística da educação no jornal Folha de $S$. Paulo entre os anos 1973 e 2002. O autor sustenta que a presença do tema teve seu espaço reduzido, principalmente depois do projeto de modernização do jornal ${ }^{1}$. Em suas considerações, ele assevera que, apesar de a educação ser apontada, em editoriais, como a principal saída para a solução dos problemas sociais brasileiros, essa preocupação não se refletiria nas matérias que retratam o cotidiano. Para ele, os espaços destinados ao tema, a falta de uma editoria específica - o fim da editoria ocorreu com a modernização do jornal - e a concentração de fontes ligadas à elite educacional fizeram com que a educação tivesse uma função mais burocrática e não um papel de destaque na linha editorial do jornal.

Muitas das proposições apresentadas por Cripa parecem-nos pertinentes. Contudo, detectamos em nossa investigação que as matérias sobre educação são encontradas em quase todo o espaço do jornal: reportagens de bairro, notícias econômicas e artigos de opinião, mormente de políticos, acadêmicos e especialistas. $\mathrm{Na}$ ausência de uma editoria que concentrasse o assunto, ele acabava por permear outros temas abordados, o que evidencia o fato de a educação escolar fazer-se presente em boa parte do repertório do jornal.

De todo modo, cabe-nos apontar que não nos dispusemos, no presente estudo, a vasculhar uma razão subjacente a tal difusão, mas sim a tomar os enunciados em sua superfície fática, compreendendo que esses, por mais banais que possam parecer, materializam a força de uma enunciação regulatória que se efetiva no dia a dia, em cada leitura. 


\section{A EDUCAC̦ÃO NO JORNAL: CONTORNOS DE UM MAPA}

Na década analisada em nosso estudo, visualizamos uma numerosa quantidade de matérias publicadas a respeito da educação. Realizando um cômputo aproximado e meramente ilustrativo, registramos uma média de 80 textos mensais em que a temática da educação escolar é mencionada. Excluídos aqueles que não tinham a educação como foco principal, obtivemos cerca de 27 textos mensais, ou seja, pouco menos de um por dia. A temática educacional apenas é ultrapassada, em quantidade, pela política (em média, 260 matérias mensais) e pela economia (em média, 200). Levando-se em conta que aos dois assuntos mais recorrentes são reservados cadernos e colunas específicas, é possível concluir que a educação escolar usufrui de um lugar de destaque na linha editorial do jornal analisado.

$\mathrm{Na}$ estrutura do jornal analisado, o tema da educação escolar aparece primordialmente na forma de notícias e de reportagens: ambas modalidades de texto jornalístico que se propõem a transmitir informações isentas, por meio de abordagens diretas e explicativas, distinguindo-se no que se refere ao aprofundamento investigativo realizado no caso das reportagens. Nessas, fatos e testemunhos são apresentados, sendo que, algumas vezes, recorre-se a fontes secundárias, como a opinião de especialistas. Chama a atenção também a incidência do tema educação em artigos assinados. Diferentemente das notícias e reportagens, nos artigos, os autores - em geral, especialistas, empresários e políticos - tecem comentários, levantam questões, discutem posicionamentos, argumentam em favor ou contra determinadas ideias etc.

Diante do total de 3.267 matérias triadas na década analisada, foram eleitas 449 para o trabalho de aprofundamento analítico. Tal recorte priorizou as matérias que tomavam a própria educação como tema principal ou exclusivo, posto que muitas das referências ao assunto ocorriam como tema secundário ou de apoio a, por exemplo, proposições econômicas e/ou políticas. A fim de propiciar o delineamento de um fio discursivo presente nas matérias, valemo-nos de quatro palavras-chave como categorias gerais de processamento do material, as quais foram eleitas devido à frequência de tais enunciados na composição das imagens em voga sobre a educação escolar naquele jornal. Foram elas: 1) qualidade, 2) formação, 3) investimento e 4) currículo. Cabe-nos salientar que, em todas as 449 matérias selecionadas, ao menos uma dessas quatro palavras-chave foi referida. 
Foi possível reconhecer, ademais, que as matérias selecionadas distribuem-se com regularidade durante os dez anos focalizados, não havendo nenhuma prevalência significativa de uma categoria sobre a outra, o que parece demonstrar uma circularidade reiterativa da linha editorial da Folha de S. Paulo em relação à educação nacional.

As temáticas mais abordadas nas 449 matérias foram: 1) a educação como solução para os problemas do país e para o bem-estar da população; 2) a formação do professor; 3) a questão da avaliação; 4) o problema da qualidade; 5) a violência; e 6) a dicotomia entre educação pública e privada.

Os textos apresentaram-se predominantemente no caderno intitulado Cotidiano, que congregou mais de $70 \%$ do total das matérias; trata-se de uma seção do jornal que se utiliza da heterogeneidade dos acontecimentos cotidianos para noticiar e dissertar sobre vários assuntos, interligando os fatos diários. Encontramos também uma parcela significativa de matérias sobre o assunto no caderno Opinião, em que se mesclam editoriais, colunas de articulistas e uma seção intitulada Tendências e Debates, a qual reúne artigos assinados por personalidades - empresários, políticos e acadêmicos - empenhadas no debate de temas de destaque e/ou polêmicos; nessa fração do diário foram publicados aproximadamente $20 \%$ das matérias sobre educação. Por fim, os outros 10\% encontravam-se distribuídos em cadernos diários - como Dinheiro, no qual é abordada a conjuntura econômica, e Mundo, que abrange as principais notícias internacionais - e também em suplementos semanais - tais como Folhateen, destinado ao público jovem, Informática, que auxilia os leitores a melhor entender e utilizar a internet $\mathrm{e}$ os computadores, Equilíbrio, dedicado a questões de saúde e qualidade de vida, e o extinto Sinapse, elaborado para promover o enriquecimento cultural dos leitores. A educação desponta, assim, como um vetor temático que se mescla a outras pautas diárias, sendo atravessado por conteúdos diversos e, ao mesmo tempo, permeando um vasto contingente de assuntos. Verificamos que a questão educacional, devido à porosidade e à versatilidade que lhe são conferidas, materializa-se como um dos nichos temáticos privilegiados na abordagem jornalística.

Grosso modo, o discurso da Folha de S. Paulo sobre a educação formal na década por nós pesquisado caracteriza-se por um caráter, presumidamente, tão crítico quanto propositivo, funcionando de acordo com um movimento linear: relatam-se fatos, apresentam-se críticas para, em seguida, proporem-se 
ações reparatórias ou reformistas. Pudemos, nesse sentido, classificar as matérias selecionadas em três tipos: denunciativas, preventivas e prescritivas. Tal divisão configura tão somente um modo aproximativo das disposições predominantes, pois os três tipos muitas vezes aparecem simultaneamente.

As matérias denunciativas, em geral, comunicam o descaso das autoridades públicas com a educação, anunciam as improbidades com o erário, revelam as diversas formas de violência presentes nas escolas e alertam para a baixa qualidade da educação pública, enunciando a iminência de uma formação precária dos alunos. Um dos editoriais descreve:

Mas o tamanho do desafio que décadas e décadas de descaso educacional produziram é grande demais: $57,64 \%$ dos brasileiros com mais de 15 anos, isto é, um exército de 69,7 milhões de pessoas, têm menos de oito anos de estudo, o que significa que não completaram o ensino fundamental [...] (NEM, 2002).

As matérias preventivas oferecem, por sua vez, um conjunto de medidas que visam evitar os males antes anunciados, por exemplo, a intervenção das empresas do terceiro setor como solução para implementar a alegada qualidade da educação nacional.

Treinamento especial de professores e aulas criativas, com uso de recursos multimídia, atividades ao ar livre e construção de brinquedos para aprender física e matemática são alguns dos elementos que ONGs, fundações, institutos e empresas usam para tornar a escola mais atraente [...] (LEITE, 2003).

Finalmente, as matérias prescritivas explicitam, entre outras coisas, como fazer a escola funcionar de um modo supostamente correto, oferecendo uma espécie de receituário com vistas a um ensino produtivo e revelando fórmulas de capacitação continuada. Encontramos aqui colunistas que descrevem soluções para a dita ineficiência da educação escolar:

O que fazer, então? Por um lado, agir sobre aquelas variáveis comprovadamente eficientes, como instalações físicas e humanas básicas nas escolas e uso do livro didático. [...] Sanar essas deficiências é condição necessária para uma educação de boa qualidade, mas certamente insuficiente. Ao fim e ao cabo, a educação é um diálogo entre professor e aluno. O salto de qualidade só virá quando o professor tiver mais conhecimento e estímulo [...] (IOSCHPE, 2005). 
As vozes encontradas nas matérias sobre educação são múltiplas e quase nunca dissonantes. Uma vez que o discurso mostra-se coeso e praticamente sem rupturas, o fator diversidade advém da eleição das testemunhas e dos analistas. Utilizando uma divisão arbitrária para facilitar a classificação dos dados - como vimos, todos os elementos são mesclados no corpo dos textos -, podemos categorizar tais vozes em três grandes blocos.

O primeiro deles é formado pelos protagonistas diretos da educação escolar: professores, alunos, coordenadores/supervisores e pais. Nesse segmento, usualmente, os depoentes descrevem os fatos em questão na matéria, expediente esse que se presta, ao que parece, tão somente para legitimar aquilo que ali é narrado pelo jornalista. É o caso do pronunciamento de uma mãe que transferiu o filho de uma escola estadual para uma particular:

$\mathrm{Na} 6^{a}$ série, seu filho, V.C.P., não sabia interpretar textos. "Eles passam de ano, mas não formulam frases nem interpretam o que lêem. $\mathrm{Na} 5^{\mathrm{a}}$ ou na $6^{\mathrm{a}}$ ainda lêem como crianças de $1^{a}$ série. O país pode mostrar lá fora que tem um nível de analfabetismo menor, mas, na prática, está formando analfabetos funcionais", critica (GOIS, 2003).

O segundo bloco é integrado por especialistas que não estão ligados diretamente à lida escolar. Nesse estrato, despontam professores universitários, pesquisadores de fundações estatais e de organizações da sociedade civil, psicólogos, médicos e funcionários de organizações internacionais voltadas à educação, enfim, uma numerosa quantidade de profissionais que se dedicam a avaliar o funcionamento das práticas escolares. Sua participação se dá, em geral, por meio de informes de pesquisa que visam autenticar ou refutar informações, além de depoimentos cientificamente autorizados. É o que vemos a seguir.

"O roubo se tornou algo secundário, normal. Foi completamente banalizado. Muitas vezes os alunos reclamam, mas não têm resposta de diretores ou professores. Isso faz com que se sintam vulneráveis", afirma a socióloga Miriam Abramovay [...] (CONSTANTINO, 2004).

Já no terceiro bloco temos o estamento dos formadores de opinião, tidos como comentaristas sociais supostamente qualificados. Suas ideias podem refutar ou franquear alegadas verdades. Encontramos aqui a informação caracterizada como um espetáculo, no qual as ideias do formador funcionam 
como uma convocação. Sua opinião, apesar de não ser de um especialista, é bastante valorizada. Participam desse bloco principalmente jornalistas e empresários e suas manifestações se dão, em geral, por meio de artigos assinados. Temos o exemplo do empresário Antônio Ermírio de Moraes, ex-presidente de um conglomerado industrial, que pontifica:

A sociedade moderna não dá espaço para pessoas deseducadas ou mal preparadas. As exigências da cidadania e do mercado de trabalho são crescentes. Só com uma educação de boa qualidade se consegue formar seres humanos que conduzam bem sua vida e contribuam para o progresso econômico e social da nação [...] (MORAES, 2004).

As vozes autorizadas a proferir a verdade sobre a educação buscam assegurar uma espécie de salvação de um mundo escolar desprovido de eficiência e serventia. Assim, os especialistas e os formadores de opinião apresentam denúncias, cobram atitudes, examinam alternativas. Suas falas têm um timbre afirmativo, ancoradas na prescrição sobre como alcançar uma boa educação e indicando o que defendem ser o melhor caminho para essa instituição secular sempre tão problemática.

Operando segundo a regra de fixação (FOUCAULT, 2002), o discurso jornalístico, no caso por nós investigado, propaga-se como uma campanha, o que se evidencia principalmente devido à aparente homologia de suas argumentações. Vejamos como isso se dá.

Em primeiro lugar, as matérias, recorrendo a gráficos e pesquisas estatísticas, investem na culpabilização da escola, do sistema educacional, dos professores e dos alunos pelo chamado fracasso da educação. Tais textos expõem, por exemplo, a falta de civilidade dos alunos, a ineficiência das avaliações e a ausência de boa formação e capacitação dos profissionais, dentre outras frentes argumentativas.

Além disso, o discurso sobre educação oferecido pela Folha de $S$. Paulo associa-se a outros discursos de modo transversal, ou seja, ele transpassa e é transpassado por outros enunciados (econômicos, políticos, sociais). É comum, como já dito aqui, encontrarmos matérias sobre educação em que a economia e a conjuntura política fazem parte do embasamento lógico apresentado nos argumentos utilizados. Do mesmo modo, os cadernos específicos de economia e política são repletos de artigos de opinião que abordam a educação e suas configurações, enaltecendo um caráter essencial 
e determinante. Por exemplo, nas palavras de Benjamin Steinbruch, ex-presidente da Companhia Siderúrgica Nacional,

[...] o chamado "milagre econômico" dos anos 60 e 70, quando a economia brasileira espantou o mundo por sua capacidade de crescimento, talvez tenha sido mais resultado do investimento em educação nas décadas anteriores do que propriamente de políticas econômicas milagrosas. [...] É melhor tentar revigorar o ensino estadual e municipal, até porque já sabemos que isso é possível, pela experiência dos anos 50 e 60. Seria útil ao debate nacional pré-eleições em que os candidatos mostrassem suas propostas concretas para reerguer a escola pública básica e formar novas gerações de cidadãos brasileiros que possam se orgulhar de seu país [...] (STEINBRUCH, 2002).

O discurso jornalístico a respeito da educação forjado pela Folha de $S$. Paulo parece, em suma, valer-se de uma polifonia de vozes e, paradoxalmente, de uma uniformidade argumentativa. À moda de uma fita de Moebius, com movimentos cíclicos e ritmados, compõe-se um jogo de bases implícitas, contrapondo ideias que se podem confrontar na forma mas que resultam cativas de fundamentos semelhantes, quando não idênticos.

\section{A EDUCAC̣ÃO ESCOLAR E A PAUTA JORNALÍSTICA: PROBLEMATIZAC̣ÕES}

A fim de problematizar a produção discursiva veiculada nos textos jornalísticos ora em análise foi necessário distanciarmo-nos das naturalizações que se processam na intrincada rede de enunciados acerca da educação escolar. Isso porque a racionalidade apregoada nas matérias analisadas constitui um conjunto de procedimentos e saberes considerados desejáveis e úteis para a conformação de sujeitos que saibam dirigir suas próprias condutas - uma sofisticada estratégia de condução de condutas que visa, num só tempo, a si e aos outros. Assim, a estratégia que se impõe nos enunciados jornalísticos da Folha de S. Paulo pode ser descrita como da ordem de uma demanda inequívoca de intervenção: instrumentalizar e tornar factível a ação sobre aquilo que ali se esquematiza de modo, em geral, peremptório.

$\mathrm{Na}$ intrincada malha do discurso jornalístico analisado em nosso estudo, propagam-se determinados modos de organização do mundo e da vida, por meio de convocações constantes para se alcançar uma existência 
plena, autônoma e responsável. A civilidade, a produtividade e a racionalidade estão em pauta quando se elege um ideal de educação, assim como quando se deprecia a realidade educacional narrada por prospecções negativizadas. A série de elementos que o jornal em questão apresenta como constitutivos da educação escolar arregimenta um processo de veridicção da realidade educacional que, no interior de uma rede de ressonâncias discursivas, opera como um expediente eficaz de controle das condutas não apenas dos escolares mas também da comunidade que se serve das escolas.

O discurso sobre educação é significado como um importante regulador da estabilidade e do desenvolvimento da vida. Os textos constroem uma realidade, a qual é relatada, comentada, e também recondicionada e remodelada por intermédio de um discurso autorizado e autolegitimado, arregimentando as fronteiras de inteligibilidade e, portanto, de veridicção sobre uma lida educacional desejável. Em outros termos: uma realidadeproblema é constituída; fatos sobre ela são narrados; pesquisas sobre o que lá acontecem são apresentadas, legitimando o verdadeiro e combatendo as falsidades; encaminhamentos são sugeridos; a responsabilidade de cada qual é apontada e enaltecida.

Numa trama complexa, os escritos jornalísticos aqui analisados operam em consonância com as produções acadêmicas, os saberes dos especialistas e as injunções econômicas e políticas, formando uma urdidura orientada por um discurso competente sobre a escola. A carência e a obsolescência afiguram-se como os principais argumentos das matérias analisadas, ou seja, a escola é definida a partir de suas deficiências ou de seus desajustes flagrantes em relação a certa concepção idealizada de educação.

Pode-se dizer que três regularidades argumentativas molares despontam na composição das significações sobre a escola junto à Folha de S. Paulo: seu caráter indispensável, o alarido pela qualidade e a instigação de sen anacronismo. Nos textos analisados, a escola, mesmo sendo descrita como um espaço problemático, é apresentada como uma instituição que não pode ser negligenciada pela sociedade, pois congregaria a tarefa magna de edificar alunos/cidadãos. O caráter de indispensabilidade da educação escolar ancora-se na premissa de que o trabalho pedagógico seria a chave para a conquista da autonomia, esta compreendida como uma espécie de maioridade que transformaria o indivíduo em um sujeito livre para fazer suas próprias escolhas. Por exemplo: “[...] apenas a educação consegue dar 
aos indivíduos autonomia, capacidade de dirigir sua vida, guiando-se pelo direito de optar" (FESTA..., 1998).

A descrição de uma educação de qualidade compreende uma escola que teria como missão produzir nos alunos as competências cognitivas necessárias e que seria simultaneamente, segundo Maria Alice Setubal (1997), "norteada por princípios de justiça social, de inclusão e de cidadania". Na ausência de uma definição conclusiva sobre o critério da qualidade, dá-se destaque justamente à sua falta. A busca de uma suposta qualificação dos fazeres escolares, assim, inocula sua ausência como marca principal da atualidade educacional.

Tal lógica discursiva, como vimos, tem por objetivo gerar uma tensão - a ausência de uma educação que seja abrangente e eficiente - e conduzir a um redirecionamento - as convocações dos especialistas representantes dos saberes validados -, criando assim um sólido eixo argumentativo da discursividade jornalística em questão.

A falta desponta, pois, como o âmago da produção de um campo de verdade que define a escola, tal qual ela se apresenta, como uma instituição inepta para suas funções básicas e, portanto, dependente de monitoramento externo, inclusive e fundamentalmente da própria mídia. Como superação de tais problemas, são oferecidas algumas opções regulatórias para a elaboração de uma educação ideal. Vejamos um exemplo:

É imprescindível que as escolas ofereçam ações educativas, preventivas e de promoção da paz, que ajudem a melhorar a autoestima dos alunos e a aumentar o envolvimento dos professores e da comunidade. Crianças e jovens precisam voltar a enxergar a escola como um local agradável de aprendizado e de troca de experiências que os levem ao sucesso na vida adulta. Os pais e as comunidades deveriam ter de novo o sentimento de pertencimento e de identidade com a escola. Assim, o espaço escolar voltaria a ser visto como um "porto seguro" a ser preservado, constituindo-se em fonte de esperança dos jovens por um futuro melhor [...] (WERTHEIN, 2004).

A elaboração identitária da escola brasileira nos enunciados jornalísticos analisados recobre ainda as cogitações sobre o descompasso entre a prática pedagógica e um mundo em constante mutação. Daí as propostas de modernização da escola por meio de um amplo conjunto de mudanças que apontem para novas formatações curriculares, via incorporação de novos conteúdos ou disciplinas, bem como via reformulação dos métodos didáticos. 
O descompasso é sinalizado pelo viés da indiferença dos alunos em relação às aulas. Relata-se que "[...] a escola é chata. [...] o jovem tem razão quando diz que não tem interesse em estudar. Ele não se identifica com a escola porque ela não tem a cara dele [...]" (AVANCINI, 2000). Ou ainda, que "[...] o aluno precisa ser mais seduzido para a educação. De repente, tudo foi evoluindo demais no mundo, e a educação é inflexível [...]” (PEREIRA FILHO, 2002).

Afirmações sobre a inutilidade dos conteúdos e o anacronismo das didáticas tornam-se cantilena nos textos jornalísticos. A solução apontada para tal? "É preciso mudar a escola internamente, por meio de um projeto pedagógico [...]” (AVANCINI, 2000).

Chama atenção a constância da atribuição de uma obsolescência à escola, o que abrange o descompasso entre o que é ensinado nas escolas e o modo como isso é realizado, de um lado, e os interesses e as necessidades do alunado, de outro. Há, portanto, um estímulo para que, juntamente com outras instâncias, a escola produza a reelaboração de currículos, métodos e posturas docentes. Tratam-se de enunciados que oferecem um conjunto prescritivo de procedimentos a fim de que a escola ultrapasse o estágio em que se encontra.

As soluções apresentadas nas páginas da Folha de S. Paulo ora por políticos, ora por pesquisadores e ainda pelos próprios professores, são bem parecidas umas com as outras e perseguem dois alvos principais: a formação e o investimento.

O tema da formação docente é quase unânime. Em praticamente todas as matérias que tratam do assunto atribuem-se a essa formação poderes de salvação ou de danação: um estudo da Unesco, por exemplo, "[...] mostra o Brasil como campeão da América Latina em repetência escolar [...] e o Ministério da Educação atribuiu os péssimos resultados obtidos à má formação dos professores [...]" (ETERNA..., 2002). Tal argumento associa-se, de imediato, à urgência do investimento na formação continuada desses profissionais.

A valorização da formação constitui um argumento que insere os professores num processo cíclico interminável de treinamento e de estudos, composto de práticas que ambicionem ultrapassar o domínio dos conteúdos não apenas via aprimoramento técnico-pedagógico, mas também por meio da qualificação moral do sujeito escolar. 
Simultaneamente à formação dos professores, propõe-se uma atenção especial à função dos diretores escolares. A frequência das reflexões sobre esses profissionais é menor do que a daquelas voltadas aos docentes, mas apresenta uma característica estratégica: é na capacitação ou no treinamento, como afirmam alguns dos textos, que se encontraria uma das chaves para alcançar a almejada qualidade, já que "[...] sem bons diretores, não existem boas escolas. O bom gestor é um empreendedor social, capaz de motivar os professores, a família e a comunidade [...]" (DIMENSTEIN, 2004).

O currículo escolar também é contemplado com prescrições salvacionistas. Exemplos disso são as iniciativas de abordagem de temas como conscientização ambiental, saúde mental, educação financeira etc.

As sugestões de novos conteúdos atuam numa zona de produtividade dos currículos (SILVA, 2003), a qual opera não apenas no plano discursivo mas ganha corpo em procedimentos técnicos, esquemas normativos de comportamento, certos tipos de transmissão de saberes e, claro está, modalidades pedagógicas específicas.

Outro ponto de intervenção vai na direção de abrir a escola (no caso, pública) à comunidade e convocar a participação dos pais na educação escolar de seus filhos. Não encontramos, porém, nenhuma matéria que sugerisse o mesmo movimento para as escolas privadas. Nesse caso, a convocação dá-se em prol do voluntarismo educativo, voltado à colaboração para a formação de um país socialmente mais justo.

Nas matérias que apregoam a integração da escola com a comunidade, despontam três objetivos fundamentais: a melhoria do ensino, o reforçamento da segurança e o oferecimento à comunidade de um espaço de lazer e cultura. Mescladas em intenção, as propostas ali veiculadas anteveem o espaço escolar como um grande centro socializador que atuasse para além de seus muros, afetando todos aqueles que, de um modo ou de outro, dele compartilham.

O processo de abertura das escolas apresenta um duplo viés. Primeiro, trata-se de convocar a participação dos pais e da comunidade, trazendo-os para dentro de seus muros. Segundo, trata-se de responsabilizar a sociedade como um todo pela educação de seus cidadãos, convertendo a escola em um espaço de regulação social por meio do qual são difundidos à população hábitos saudáveis e mais adequados, aumentando a possibilidade de alcance de suas práticas regulatórias. Assim, outros sujeitos são chamados a participar das atividades propostas para apropriação da escola como espaço cultural e esportivo. 
A abertura de escolas nos finais de semana para a comunidade, com atividades de cultura, lazer e esporte - criada por meio do Programa Abrindo Espaços, lançado em 2000 pela Unesco -, demonstra ter forte impacto positivo no resgate da imagem da escola, na melhoria da qualidade do aprendizado de crianças e jovens e na redução da violência no espaço escolar e no seu entorno [...] (WERTHEIN, 2004).

Os enunciados sobre a comunidade e seu envolvimento nos projetos educativos figuram como propostas de condução a uma unificação que parece não se sustentar por completo. Nesse jogo argumentativo, articula-se uma incitação coletiva no intuito de agregar, em torno de valores e ideais essencialistas, sujeitos dispersos. Há a convocação a uma fusão comunial por meio da qual se produz um apelo à dignidade, à vida e ao bem-estar. Reunir escola e comunidade, nessa perspectiva, seria partilhar valores, melhorar hábitos etc. Tal convocação opera como predição de uma razão comum, garantindo a fixação de um tipo de sujeito cuja existência está vinculada à possibilidade desse exercício de comunhão.

\section{A MÍDIA IMPRESSA E OS PROCESSOS DE GOVERNAMENTALIZAC̣ÃO EDUCACIONAL}

Na Folha de S. Paulo, a educação escolar parece, de algum modo, ter-se convertido em espetáculo. Os textos a definem como uma prática social a reboque de modelos ideais, sendo constantemente construída e reconstruída segundo imagens apologéticas. O mundo da escola torna-se, então, um imenso parque de fulgurações que oferece imagens a serem contempladas, consumidas ou refutadas. A partir delas, os sujeitos vivenciam ideias e valores a reboque de um discurso construído cotidianamente, sempre em conexão com outros enunciados que produzem certa realidade, em certo tempo e por certo período.

Podemos deduzir, então, que o papel da imprensa escrita é fundamental no jogo produtivo da veridicção sobre os afazeres praticados nas escolas, não no intuito de alienar o sujeito por meio de representações falseadas de uma suposta realidade-matriz, mas no de constituir um repertório de validação/recusa do que lá se passa. Os ditos sobre a educação escolar são autorizados e legitimados, contribuindo ativamente na forja do que 
entendemos e vivenciamos como a verdade da educação atual. Assim, as palavras de ordem circulantes sobre a instituição escolar e seus encargos passam a tomar parte do processo de veridicção da realidade escolar, regulando seu funcionamento cotidiano.

Tal arte de governar foi denominada por Foucault de governamentalidade. Trata-se de uma racionalidade de governo centrada nas problemáticas da população, da economia e da segurança. Sua tecnologia multiforme age de maneira abrangente e apurada, articulando-se em uma consonância de saberes e incidindo sobre os sujeitos de forma a balizar, regular e normalizar suas condutas. Por intermédio de práticas de governamentalização, a vida das populações é ordenada e, ao mesmo tempo, opera-se uma crescente normalização da existência individual.

Governamentalidade, assim, diz respeito diretamente à condução da conduta de um grupo de indivíduos, em suas dimensões capilares. Ela

[...] incide sobre os corpos individuais e coletivos regulando, marcando, normalizando e individualizando; induz efeitos de subjetividade, produz subjetivações; concerne à vida dos indivíduos, dirige-se à sua conduta, envolve técnicas de governo de si mesmo [...] (PRADO FILHO, 2006, p. 19).

Ao analisar a iminência das práticas de governamentalização expressas nos enunciados jornalísticos em circulação na Folha de S. Paulo, deparamos com um discurso que encerra técnicas e modos de regulação visando a geração de certas subjetividades afinadas à norma. Governar, nesse sentido, significa conduzir condutas em um duplo aspecto: tanto em referência à "atividade que consiste em conduzir", quanto à "[...] maneira pela qual conduzimos a nós mesmos, o modo pelo qual nos deixamos conduzir, a maneira pela qual somos conduzidos e pela qual, enfim, nos comportamos sob efeito de uma conduta [...]" (FOUCAULT, 2008, p. 197). A atividade de conduzir condutas é, portanto, inseparável da maneira de conduzir e da atitude de resistência a uma condução específica. Há, nesse movimento, uma responsabilização dos indivíduos, levando-os a uma tomada de decisão supostamente livre. O processo de governamentalização, no âmbito jornalístico aqui analisado, efetiva-se, ademais, pela desqualificação do presente escolar - baixo desenvolvimento, atraso econômico, violência, desigualdade etc. - em favor de um futuro mais orgânico, mais desenvolvido, mais promissor. 
É possível admitir, assim, que a educação desenhada nas pautas jornalísticas da Folha de S. Paulo finda por apresentar-se em oposição àquela que é ali denunciada. Tratar-se-ia da positivação de uma educação diferenciada, legitimada por estudos acadêmicos e encontrada em países desenvolvidos e em algumas poucas escolas privadas.

Afirma-se, desse modo, uma gestão das condutas de tipo pastoral (FOUCAULT, 2008), a qual se efetiva por meio da convocação, da persuasão e do aliciamento dos sujeitos. Isso porque a prática discursiva materializada pelos enunciados jornalísticos por nós investigados atuaria de modo consoante a um movimento segundo o qual o sujeito deve ser educado e convencido a engajar-se em uma espécie de aliança íntima entre suas ambições pessoais e determinadas atividades institucionais socialmente valorizadas. É à distância e a céu aberto, pois, que esse tipo de governamento opera.

Mais especificamente, a discursividade jornalística aqui em foco reproduziria e reforçaria conceitos - autonomia, democracia, responsabilização, comunhão etc. - que dão sustentação a uma lógica econômica e política com vistas à edificação de práticas capazes de gerar cidadãos produtivos e conscientes de seus direitos e deveres.

Por meio de apelos que estabelecem balizas prescritivas de conduta e pensamento, irrompe uma abundância de racionalidades promotoras de uma educabilidade geral de formas e modos de vida: deve-se aprender a viver de determinado modo, a partir de certos valores e para fins específicos. $\mathrm{O}$ viver torna-se matéria a ser aprendida, habilidade a ser desenvolvida, competência a ser adquirida. Tem-se aí, claro está, um projeto ético-político que prioriza, entre outras coisas, obrigações voluntariamente assumidas por indivíduos livres que poderiam tirar maior proveito de sua própria existência mediante uma gestão mais responsável de sua vida.

Como já dito, na marcha argumentativa da Folha de S. Paulo, a escola é insistentemente chamada a abrir-se para a comunidade, que, por sua vez, é convidada a colaborar com o aperfeiçoamento da instituição. Nesse interjogo de influências recíprocas, há novamente um chamado à salvação que traz em seu âmago uma ação de cuidado: cada integrante deveria cuidar do outro e todos deveriam zelar pela instituição. Tal cuidado recíproco constitui uma rede de monitoramento convocada a atuar sobre as práticas cotidianas, tornando a comunidade um referente-chave no processo de governamentalização educacional. Conjuga-se, dessa forma, um controle 
mútuo apoiado em determinados padrões sobre o que é ou não correto fazer, por meio da disseminação de uma forma política e pedagogicamente correta de agir e, por extensão, de um modo tão sutil quanto acirrado de regulação das vidas escolares.

A comunidade, noção abrangente, porosa e maleável, permitiria a expansão das intervenções educacionais para além dos muros da escola: ela educa e é educada enquanto o entorno cuida e é cuidado. Valendo-nos das ideias de Peter Pál Pelbart (2003) sobre o pensamento de Jean-Luc Nancy, reafirmamos a premissa de que a noção de comunidade figura como uma grande ilusão produzida pelo projeto moderno, o qual intencionou forjar um sujeito constituído pela imagem de um corpo comum, esta viabilizada por uma identificação fundada no pertencimento. A convocação a tal pertencimento investe em relações capilares de associação com vistas à formação de um cidadão integral. Sob a rubrica de ações pedagógicas, naturaliza-se a proposta de uma intervenção baseada na suposição de que apenas a sociedade como um todo seria capaz de construir uma educação de qualidade.

Tal movimento remete, ao menos em parte, a uma desobrigação formal do Estado, por meio da desvinculação, pelas instâncias governamentais, da responsabilidade sobre um conjunto de questões sociais. Desta feita, o processo de descentralização, flexibilização e fortalecimento da sociedade civil finda por operar concomitantemente à formação de um sujeito que não mais possui a opção de recusar o que lhe é decretado pelo mesmo Estado que, ao empoderá-lo, abandona-o à própria sorte. Como bem explica Giorgio Agamben (2010), trata-se de

[...] uma outra e mais dissimulada operação do poder, que não age imediatamente sobre o que os homens podem fazer - sobre sua potência -, mas antes sobre a sua impotência, isto é, sobre o que não podem fazer ou, melhor, podem não fazer $[\ldots]$ (p. 57).

$\mathrm{Na}$ contemporaneidade, os homens são constantemente incitados a levarem a cabo uma pletora de ações (auto)edificantes, estando, no mais das vezes, impedidos de recusarem tais demandas; é, pois, nesse combate à recusa que "prefere agir o poder que se define ironicamente como 'democracia”" (p. 58).

Os textos jornalísticos tratados em nosso estudo apontam que a escola precisaria ser muito mais do que ela um dia já foi. Controlar os (des) 
caminhos dessa instituição desponta como uma das estratégias seguidas à risca por aqueles que ecoam suas vozes nas páginas do jornal investigado, decretando não apenas a verdade ali apresentada, mas também o papel político que ela exerceria sobre os viventes. Nesse sentido, prosseguimos com Foucault (2006b) ao definir o que aqui está em causa: “a questão política não é o erro, a ilusão, a consciência alienada ou a ideologia; é a própria verdade" (p. 14).

Ao ser lido, repetido e legitimado, o discurso jornalístico sobre a educação, aqui pontualmente escrutinado, concretiza a afirmação de um mundo exclusivo e a supressão de outros possíveis. As palavras de ordem por ele proferidas atam os indivíduos a uma implacável política de veridicção, sem explicitar, porém, que a verdade ali professada é tão inventada quanto a vida que ela contém. 


\section{REFERÊNCIAS}

AGAMBEN, G. Nudez: Lisboa: Relógio D’Água, 2010.

CANCIAN, E. P. F. O discurso de uma revista especializada em educação: um olhar sobre a construção metafórica do professor. 2008. 81 f. Dissertação (Mestrado em Linguística)Pontifícia Universidade Católica, São Paulo, 2008.

COSTA, M. V. (Org.). Estudos culturais em educação: mídia, arquitetura, brinquedo, biologia, literatura, cinema. Porto Alegre: Ed. Universidade/ufrgs, 2000.

COSTA, M. V. Ensinando a dividir o mundo: as perversas lições de um programa de televisão. Revista Brasileira de Educação, Rio de Janeiro, n. 2, p. 71-82, mai./ago. 2002.

CRIPA, M. L. Cobertura da educação no jornal Folha de São Paulo: uma análise comparativa dos anos 1973 e 2002. 189 f. Dissertação (Mestrado em Ciências da Comunicação)-Escola de Comunições e Artes, Universidade de São Paulo, São Paulo, 2008.

DELEUZE, G. O ato de criação. Folha de São Paulo, São Paulo, 27 jun. 1999. Caderno Mais, p. 4-5.

DELEUZE, G. Foucault. São Paulo: Brasiliense, 2006.

DELEUZE, G.; GUATTARI, F. Postulados da lingüística. In: DELEUZE, G.; GUATTARI, F. Mil platôs: capitalismo e esquizofrenia. Rio de Janeiro: Editora 34, 2008. v. 2, p. 11-59. ERIBON, D. Michel Foucault. 1920-1984. São Paulo: Companhia da Letras, 1990.

FISCHER, R. M. B. Adolescência em discurso: mídia e produção de subjetividade. 1996. 297 f. Tese (Doutorado em Educação)-Faculdade de Educação, Universidade Federal do Rio Grande do Sul, Porto Alegre, 1996.

FONSECA, A. P. A. A construção da educação na revista Veja. 2008. 116 f. Dissertação (Mestrado em Comunicação)-Pontifícia Universidade Católica, São Paulo, 2008.

FOUCAULT, M. Resumos dos cursos do Collège de France (1970-1982). Rio de Janeiro: Jorge Zahar Editor, 1997.

FOUCAULT, M. Os anormais. São Paulo: Martins Fontes, 2002.

FOUCAULT, M. A ordem do discurso. São Paulo: Edições Loyola, 2004.

FOUCAULT, M. A verdade e as formas jurídicas. Rio de Janeiro: Nau, 2005.

FOUCAULT, M. O nascimento da clínica. Rio de Janeiro: Forense Universitária, 2006a.

FOUCAULT, M. Verdade e poder. In: FOUCAULT, M. Microfísica do poder. Rio de Janeiro: Edições Graal, 2006b. p. 1-14.

FOUCAULT, M. Arqueologia do saber. Rio de Janeiro: Forense Universitária, 2007.

FOUCAULT, M. Segurança, território, população. São Paulo: Martins Fontes, 2008.

FOUCAULT, M. Por uma moral do desconforto. In: FOUCAULT, M. Repensar a política. Rio de Janeiro: Forense Universitária, 2010. p. 279-284. (Ditos e Escritos, n. 6).

GERZSON, V. A mídia como dispositivo da governamentalidade neoliberal: os discursos sobre educação nas revistas Veja, Época e IstoÉ. 2007. 164 f. Tese (Doutorado em Educação)Faculdade de Educação, Universidade Federal do Rio Grande do Sul, Porto Alegre, 2007. PELBART, P. P. A comunidade dos sem comunidade. In: PELBART, P. P. Vida capital: ensaios de biopolítica. São Paulo: Iluminuras, 2003. p. 28-41.

PRADO FILHO, K. Michel Foucault. uma história da governamentalidade. Rio de Janeiro: Insular e Achiamé, 2006. 
RICARDO FILHO, G. S. A boa escola do discurso da mídia: um exame das representações sobre educação na revista Veja (1995-2001). 2003. 194 f. Dissertação (Mestrado em Educação)-Universidade Estadual Paulista “Júlio de Mesquita Filho”, Araraquara, 2003. ROCHA, C. M. F. A escola na midia: nada fora do controle. 2005. 289 f. Tese (Doutorado em Educação)-Faculdade de Educação, Universidade Federal do Rio Grande do Sul, Porto Alegre, 2005.

SILVA, T. T. O currículo como fetiche: a poética e a política do texto curricular. Belo Horizonte: Autêntica, 2003.

SILVEIRA, F. R. Um estudo das capas da Revista Nova Escola: 1986-2004. 2006. 149 f. Dissertação (Mestrado em Educação)-Faculdade de Educação, Universidade Estadual de Campinas, Campinas, 2006.

\section{FONTES}

AVANCINI, M. Ensino deve se ligar à realidade. Folha de São Paulo, São Paulo, 17 jan. 2000. Cotidiano. Disponível em: <http://www1.folha.uol.com.br/fsp/cotidian/ff1701200007. htm>. Acesso em: 13 abr. 2010.

CONSTANTINO, L. Escola deixa aluno vulnerável, diz Unesco. Folha de São Paulo, São Paulo, 28 abr. 2004. Cotidiano. Disponível em: <http://www1.folha.uol.com.br/fsp/ cotidian/ff2804200412.htm>. Acesso em: 26 nov. 2010.

DIMENSTEIN, G. Repetência é coisa de pobre. Folha de São Paulo, São Paulo, 18 abr. 2004. Cotidiano. Disponível em: <http://www1.folha.uol.com.br/fsp/cotidian/ff1804200426. htm>. Acesso em: 13 abr. 2010.

ETERNA repetição. Folha de São Paulo, São Paulo, 08 fev. 2002. Editorial. Disponível em: <http://www1.folha.uol.com.br/fsp/opiniao/fz0802200203.htm>. Acesso em: 26 nov. 2010. FESTA é quase uma ilusão. Folha de São Paulo, São Paulo, 07 set. 1998. Editorial. Disponível em: <http://www1.folha.uol.com.br/fsp/cotidian/ff07099814.htm>. Acesso em: 23 out. 2010.

GOIS, A. Mães criticam formação insuficiente. Folha de São Paulo, São Paulo, 22 set. 2003. Cotidiano. Disponível em: <http://www1.folha.uol.com.br/fsp/cotidian/ff2209200303. htm>. Acesso em: 26 nov. 2010.

IOSCHPE, G. Por uma educação de resultados. Folha de São Paulo, São Paulo, 07 fev. 2005. Opinião. Disponível em: <http://www1.folha.uol.com.br/fsp/opiniao/fz0702200510. htm>. Acesso em: 26 nov. 2010.

LEITE, F. ONGs ensinam governos a tornar escola mais atraente. Folha de São Paulo, São Paulo, 21 maio 2003. Cotidiano. Disponível em: <http://www1.folha.uol.com.br/fsp/ cotidian/ff2105200312.htm>. Acesso em: 26 nov. 2010.

MORAES, A. E. Um exemplo a ser seguido por todo o Brasil. Folha de São Paulo, São Paulo, 28 nov. 2004. Opinião. Disponível em: <http://www1.folha.uol.com.br/fsp/ opiniao/fz2811200406.htm>. Acesso em: 26 nov. 2010.

NEM para Gari. Folha de São Paulo, São Paulo, 19 nov. 2002. Editorial. Disponível em:<http:/ / www1.folha.uol.com.br/fsp/opiniao/fz1911200202.htm>. Acesso em: 26 nov. 2010. 
PEREIRA FILHO, A. Em São Paulo, novo secretário prioriza a segurança. Folha de São Paulo, São Paulo, 14 abr. 2002. Cotidiano. Disponível em: <http:/ /www1.folha.uol.com. br/fsp/cotidian/ff1404200205.htm>. Acesso em: 24 out. 2010.

SETUBAL, M. A. Saída para fracasso escolar. Folha de São Paulo, São Paulo, 14 jul. 1997. Opinião. Disponível em: <http://www1.folha.uol.com.br/fsp/cotidian/ff140708.htm>. Acesso em: 13 abr. 2010

STEINBRUCH, B. Ouviram do Ipiranga... Folha de São Paulo, São Paulo, 05 mar. 2002. Dinheiro. Disponível em: < http://www1.folha.uol.com.br/fsp/dinheiro/fi0503200202. htm>. Acesso em: 26 nov. 2010.

WERTHEIN, J. Por uma escola de paz. Folha de São Paulo, São Paulo, 16 set. 2004. Opinião. Disponível em: <http://www1.folha.uol.com.br/fsp/opiniao/fz1609200410.htm> Acesso em: 26 nov. 2010.

\section{NOTAS}

${ }^{1}$ O Projeto Folha é apontado como o início do jornalismo moderno no Brasil. Teve como objetivo implantar uma nova política editorial e profissional, bem como estabeleceu um conjunto de medidas que instituíam normas de escrita e de conduta, instrumentos de controle de produção, pesquisas com leitores, entre outros. Tais medidas tinham a intenção de formatar os padrões de comportamento profissional, editorial e gráfico. Uma asserção que resume adequadamente a filosofia do jornal a partir desse projeto é: "A Folha considera notícias e ideias como mercadorias a serem tratadas com rigor técnico" (fonte: <http:// www1.folha.uol.com.br/folha/circulo/ manual_projeto_intruducao.htm>).

Recebido: 10/10/2011 